\title{
Exposición, vulnerabilidad y perfil epidemiológico de trabajadores informales en el botadero a cielo abierto del cantón Portoviejo, Ecuador
}

\author{
María F. Solíz T. \\ Investigadora en el área de salud de la Universidad Andina Simón Bolívar, Quito, Ecuador. \\ Autor de correspondencia: fersolizec@ hotmail.com \\ Fecha de recepción: 5 de noviembre 2013 - Fecha de aceptación: 20 de enero 2014
}

\begin{abstract}
RESUMEN
El presente trabajo abarca un amplio estudio de la exposición, vulnerabilidad y el perfil epidemiológico de los recicladores informales y sus familias en el vertedero a cielo abierto del Cantón Portoviejo. Entrevistas y encuestas extensas posibilitaron la evaluación del proceso integrado de reciclaje y develaron detalles de las condiciones de vida y exposición ambiental de los trabajadores informales y sus familias. Además del proceso de discusión y reflexión colectiva, los trabajadores informales fueron sometidos a un examen clínico, a dos pruebas psicológicas (Epiestrés y Goldberg), y una prueba neuroconductual (Pentox). El estudio etnográfico transversal permitió la identificación y delimitación de los trabajadores informales y sus familias en 5 clases distintivas en función del tipo de actividad de reciclaje, las condiciones socio- económicas y de vida, la exposición y la vulnerabilidad a la contaminación, y el perfil epidemiológico. Se sugiere utilizar los resultados del estudio como base para un debate público por el fortalecimiento de las iniciativas de reciclaje informal así como la eliminación de la discriminación y la opresión hacia los recicladores y sus familias, que pertenecen a los estratos más pobres de la sociedad.
\end{abstract}

Palabras clave: Recicladores informales, ocupación profesional, exposición, vulnerabilidad, perfil de salud.

\begin{abstract}
The present work covered an extensive study of the exposure, vulnerability and epidemiological profile of informal waste recyclers and their families in the open recycling dump of the Canton Portoviejo. Extensive interviews and surveys helped in evaluating the mechanism of the recycling unit and in revealing details of living condition and environmental exposure of the informal workers and their family. In addition to the process of discussion and collective reflection, the informal workers were subjected to a clinical examination, two psychological tests (Epiestrés and Goldberg), and a neurobehavioral test (Pentox). The cross sectional ethnographic survey enabled the identification and delineation of the informal workers and their families in 5 distinctive classes based on the type of recycling activity, the socio-economic status and living conditions, the exposure and vulnerability to contamination, and the epidemiological profile. It is suggested to use the findings of the study as basis for a public debate on the possibility of formalizing the unorganized waste trade, and a way to remove the discrimination and oppression of the recyclers, who belong to the poorest strata of the society.
\end{abstract}

Keywords: Informal recyclers, professional occupation, exposure, vulnerability, health profile.

\section{INTRODUCCIÓN}

Durante los años de la industrialización y el período neoliberal del capitalismo se agudiza una crisis global de la basura. Este modelo de desarrollo, subsume el consumo humano, mutándolo en sus dimensiones real y formal (Veraza, 2008; Gutberlet, 2008), y generando una crisis doble de la basura, 
cuantitativa y cualitativa, en tanto se caracteriza por un incremento exponencial y una nocividad creciente. Desde una visión global de la complejidad de los flujos de recursos y energía (Gutberlet, 2008), la basura, como quinto proceso del metabolismo social (Toledo y Gonzáles, 2007), es el resultado final del circuito relacional sociedad-naturaleza, y por ende constituye un reflejo de los modos productivos y reproductivos, de las relaciones de poder, de la equidad o inequidad en la distribución y consumo y de la soberanía económica y política de los Estados.

Así, la rápida urbanización y el incremento de las actividades comerciales e industriales ha devenido en la generación de grandes cantidades de basura (Rockson y col., 2013 en Zen y col., 2014) cuya composición está determinada por la naturaleza de la economía (Othman y col., 2013 en Zen y col., 2014). La generación de residuos está directamente relacionada por un lado con la densidad poblacional. Por otro lado, cantones de actividad agroindustrial, extractiva, comercial o turística, pese a su baja densidad poblacional tienen sistemas de disposición final colapsados e índices de producción de residuos per cápita muy elevados. En estos territorios la baja densidad poblacional contrasta con el alto índice de desarrollo social empresarial, es decir se trata de cantones en los cuales la crisis de la basura deviene del modelo económico territorial. Datos optimistas sugieren que únicamente entre el 30 a 70\% de la basura generada en ciudades de países en desarrollo es recolectada para disposición final, como corolario, los residuos restantes son vertidos en basurales a cielo abierto, calles y cuerpos de agua (Ezeah y col., 2013). Según Othman y col. en Zen y col. (2014) y Ezeah y col. (2013) las consecuencias del manejo inadecuado en la disposición de residuos genera múltiples problemas de contaminación del agua superficial y freática, suelo, aire, paisaje, transmisión de enfermedades, emisión de biogás (metano y dióxido de carbono), incendios, obstrucción de desagües, etc.

En la mayoría de los países, la gestión integral de residuos sólidos es una responsabilidad directa de los municipios; sin embargo, los servicios provistos son inadecuados en términos de acceso y condiciones de disposición final (Paul y col., 2012). Desde una mirada crítica, el manejo de residuos conlleva la internalización de los costos de gestión y el incremento de costos ambientales y de salud que, por lo general, son externalizados a poblaciones de recicladores y comunidades vecinas a sistemas de disposición final (Gutberlet, 2008). Surgen entonces las preguntas sobre ¿Quiénes son los verdaderos responsables de esta crisis global?, ¿Quiénes deberían cubrir los costos de la gestión?, ¿Quiénes deberían estar involucrados en la recuperación y reciclaje de residuos y cómo la generación y gestión de residuos tiene una relación estrecha con la demanda de justicia social y ambiental? (Gutberlet, 2008; Tangri, 2009; y Solíz, 2011).

Bauman (2005) en su libro Vidas desperdiciadas. La modernidad y sus parias proponen la categoría "humanos residuales" para referirse a aquellas personas que fueron expulsadas de la globalización con la intensificación de políticas neoliberales y que han debido insertarse en la economía informal, muchos de ellos en la recuperación y reciclaje de residuos. Varios estudios revelan que la contribución del sector informal en la recuperación y reciclaje de residuos municipales es mucho más alta que la realizada desde sectores formales en países en desarrollo (Wehenpohl y Kolb, 2007; Medina, 2008; Gerdes y Gunsilius, 2010; Hetz y col., 2011 en Paul y col., 2012; Zia y col., 2008 en Ezeah y col., 2013; Scheinberg y col., 2010). El trabajo en reciclaje informal históricamente se ha caracterizado por ser a pequeña escala, por el trabajo intensivo, por la ausencia de regulación, registro y reconocimiento laboral, por la baja tecnología (Wilson, y col., 2001 en Wilson y col., 2006) y la ausencia de condiciones laborales y de salud dignificantes. Los recicladores informales no pagan impuestos, no tienen licencia comercial y no se incluyen en el bienestar social o regímenes de seguro del gobierno (Haan y col., 1998 en Wilson y col., 2006). A nivel global, el reciclaje informal es llevado por minorías y grupos sociales marginados que encuentran en las actividades de recolección y reciclaje ingresos para la supervivencia familiar diaria. Esta situación se ha generalizado en las zonas urbanas de los países en desarrollo, en ciudades de Asia y América Latina, aproximadamente el 2\% de la población depende de las actividades de reciclaje. (Medina, 2000 en Wilson y col., 2006; Calvo y col., 2007 en Paul y col., 2012).

Dado a que se trata de una actividad no regulada, no existen datos confiables del número actual de recicladores informales (Zen y col., 2014). En Brasil el 37\% de las municipalidades refieren tener recicladores informales separando los residuos en vertederos a cielo abierto, identificando un mínimo de 45.000 recicladores informales en rellenos sanitarios y 30.000 en calles (Gutberlet, 2008). La producción de residuos per cápita a nivel mundial varía de acuerdo al nivel de industrialización, así 
países latinoamericanos como Bolivia, Perú y Argentina reportan una producción de 0,70; 0,80 y 0,85 $\mathrm{kg} \mathrm{hab}^{-1} \mathrm{día}^{-1}$. Por otro lado, países como Estados Unidos y España reportan cifras muy superiores con 2 y $1,7 \mathrm{~kg} \mathrm{hab}^{-1}$ día $^{-1}$ respectivamente (Tangri, 2009). En Ecuador, la situación de residuos sólidos sigue la misma estructura de los países en vías de desarrollo con una producción urbana de $0,81 \mathrm{~kg}$ de residuos diarios por habitante. De un total aproximado de 58.829 toneladas semanales que se producen a nivel de las 24 provincias, únicamente el $14,81 \%$ se dispone en condiciones adecuadas, el porcentaje restante se distribuye entre vertederos a cielo abierto, botaderos controlados, botaderos en vías, quebradas y ríos. El 45,73\% de municipios refiere la presencia de recicladores informales, y se estima que el porcentaje total de reciclaje (formal e informal) es de 14\%. A nivel nacional, la Gestión de Residuos es competencia de los gobiernos autónomos descentralizados (GADS) y el Ministerio del Ambiente (MAE) opera como instancia rectora. En el año 2010, el MAE sancionó a varios municipios del país debido a las condiciones de disposición final de residuos, uno de ellos, el Municipio de Portoviejo que fue declarado en emergencia sanitaria.

El basural a cielo abierto del cantón Portoviejo es uno de los sistemas más antiguos (50 años) y con mayor población recicladora viviendo dentro y en sus alrededores. La estimación del volumen promedio de residuos tratados en este cantón es de 300 toneladas diarias, de éstas, aproximadamente el $60 \%$ está constituido por residuos orgánicos, $35 \%$ por inorgánicos y el $5 \%$ restante corresponde a desechos tóxicos. La disposición final se realiza en condiciones sumamente precarias, no existe separación en la fuente, por lo que los residuos se vierten mezclados: orgánicos, inorgánicos, hospitalarios, industriales e incluso los lodos de pozos sépticos. La presencia de vectores como cerdos, gallinazos, perros, roedores e insectos es generalizada y permanente. Con una extensión de 14 hectáreas, el botadero se localiza a 3,5 km de la ciudad de Portoviejo, al término de la Parroquia urbano marginal San Pablo. En este sector, se ubican asentamientos poblacionales informales (suburbios) conocidos como Barrios El Rocío, Las Cumbres y Los Cañonazos, estos suburbios se extienden como apéndices de la parroquia San Pablo y su población se dedica exclusivamente al reciclaje. No existen registros oficiales de la población recicladora que vive en estos barrios, sin embargo, el presente estudio se construye con la experiencia de 5 años de trabajo en los que registramos un total de 100 familias recicladoras, correspondiente a 459 personas, de las cuales, 150 se dedican directamente a actividades relacionadas con la basura. El peso de materiales recuperado mensualmente por actores informales es de 253 toneladas, equivalente a 33.133 USD.

En este contexto, la presente investigación tiene por objetivo develar los mecanismos de la planta informal de reciclaje, los patrones de exposición, vulnerabilidad y las principales expresiones en salud (perfil epidemiológico) que se dan en recicladores informales y familias trabajando en uno de los vertederos a cielo abierto más grandes del Ecuador, y aspira a constituirse como un insumo que denuncia las condiciones de discrimen y opresión en las que viven recicladores/as informales y sus familias para la reivindicación de derechos laborales, sociales civiles y políticos así como su inclusión en los sistemas de gestión integral de residuos. Adicionalmente, este insumo científico pretende abrir el debate público sobre la urgencia de establecer políticas de reparación integral (restitución, indemnización, rehabilitación, satisfacción; y las garantías de no repetición de las conductas) en comunidades afectadas por disposición final de residuos.

El estudio se desarrolló a partir de procesos de Investigación Acción Participativa (IAP) articulando la metodología en función de los 3 dominios de la determinación social de la salud: contexto socio histórico, modos de vida y estilos de vida (Breilh, 2003). Algunas de las técnicas de investigación aplicadas fueron: etnografía, asambleas barriales, historias de salud barrial, familiar, personal, examen clínico, la aplicación de dos reactivos psicológicos (Epiestrés y Goldberg) y un reactivo neurocomportamental (Pentox). En función de ello, la investigación determinó la existencia de una tipología de cinco modos de vida (perfiles epidemiológicos) determinados por la actividad que cada individuo desarrolla dentro de la cadena de reciclaje: recolección, chamba, clasificación, intermediación y crianza de animales. Finalmente, el estudio compara los perfiles de exposición (procesos destructivos y magnitud), los procesos protectores, la vulnerabilidad y morbilidad en los diferentes perfiles epidemiológicos identificados. 


\section{METODOLOGÍA}

Esta investigación surge de la urgencia por realizar acciones en favor de políticas inclusivas que comprendan el reciclaje informal como una oportunidad para redistribuir ingresos (Gutberlet, 2008) y como componente fundamental de un modelo de gestión integral de residuos basado en la justicia social y ambiental que garantice condiciones de salud laboral y derechos políticos, sociales y económicos para la población recicladora. Para ello, consideramos que el primer paso es develar las condiciones laborales de exposición, vulnerabilidad y los impactos en salud de este grupo poblacional, con miras a su transformación.

El reto de establecer procesos de construcción científica con grupos vulnerables demanda una actitud de compromiso con la transformación de los contextos productores de inequidad y opresión. En palabras de Samaja (1994): "todo proceso de investigación forma parte de un desarrollo más vasto: el desarrollo de la historia en que se genera todo producto científico y a la que todo producto retorna como una condición de los nuevos procesos". Bajo esta lógica, la metodología seleccionada fue la investigación acción participativa (IAP) en tanto reconoce que el conocimiento y las experiencias locales son fundamentales en los procesos de formulación de políticas públicas consistentes (Schmelkes, 1986; Ander-Egg, 2003; Chávez y Daza, 2003). Adicionalmente, se trata de una oportunidad para que los participantes contribuyan en la generación de nuevos conocimientos (Gutberlet, 2008; Chávez y Daza, 2003; Rojas, 2002).

\subsection{Investigación Acción Participativa}

La Investigación Acción Participativa (IAP) se utiliza ampliamente en las ciencias sociales (Park, 1999 en Gutberlet, 2008). Este método se maneja con frecuencia para analizar las comunidades que se enfrentan a la privación de los derechos políticos, sociales y económicos. La IAP permite un cambio de paradigma en la comprensión epistemológica de la investigación generalmente centrada en el conocimiento representacional (Gutberlet, 2008). La investigación acción participativa constituye, sin lugar a dudas, una propuesta político epistemológica vital en la construcción de ciencia popular emancipadora (Freire, 1973; Fals Borda, 2008), es así que las categorías conceptuales y hallazgos propuestos en esta investigación se fundaron esencialmente en procesos de IAP con los barrios afectados por el sistema de disposición final de residuos. Si bien existen críticas en relación a la rigurosidad científica de la IAP, especialmente debido a que el nivel de intimidad entre el investigador y los colectivos podría influenciar los resultados (Pain y Francis, 2003 en Gutberlet, 2008). Al tener sus raíces en el Materialismo Dialéctico, la IAP se estructura en el movimiento de acción-reflexión, que con una adecuada operacionalización de la metodología, permite generar conocimiento científico al tiempo que se transforma intencionalmente la realidad (Schmerkel, 1986).

El presente estudio, forma parte de los procesos de acompañamiento e investigación acción participativa con los barrios afectados por el basural a cielo abierto del cantón Portoviejo, específicamente con los recicladores/as informales y sus familias. El diseño, las aspiraciones, objetivos, estrategias y funciones de esta investigación fueron definidos en reuniones con la Asociación de Recicladores/as así como en Asambleas Barriales. Han sido varios productos derivados de este proceso: agendas de compromisos comunitarios, reconstrucción de la asociación de recicladores, informes científicos utilizados para la construcción de política pública y para la denuncia pública (estado de salud de recicladores, impactos ambientales del vertedero, análisis desde la economía ecológica de aporte de recicladores/as informales en el sistema municipal, etc.). De esta manera, el proceso de IAP desarrollado con las familias recicladoras del botadero de Portoviejo facilitó la consolidación de procesos asociativos y de formación política, al tiempo que permitió llegar a un nivel profundo de comprensión de la determinación socio ambiental de la salud de población afectada por vertederos a cielo abierto.

\subsection{Técnicas de investigación}

Los tres aspectos que a continuación se describen - contexto socio-histórico, espacio barrial, y el nivel de vida - fueron evaluados para investigar y reconstruir patrones etnográficos, la exposición y el 
estado de salud recicladores informales de Portoviejo. Las técnicas de investigación desarrolladas en cada componente fueron las siguientes:

- Contexto sociohistórico: comprensión de la segregación sociohistórica y caracterización del modelo productivo-reproductivo del territorio reconstruido a partir de las Asambleas Barriales Participativas y Cartografía Socioambiental Participativa.

- Espacio barrial: análisis del conflicto e identificación de procesos epidemiológicos críticos, derivado del análisis etnográfico y la historia barrial participativa.

- Nivel de estilos de vida: análisis de los patrones de exposición, vulnerabilidad y salud desde la historia de la salud familiar y personal y un examen clínico que consiste en la test de Goldberg ${ }^{1}$, de Epiestrés ${ }^{2}$ (Breilh, 1993), y de Pentox ${ }^{3}$ (Breilh y col., 2012).

\subsection{Variables e indicadores del estudio}

Las variables e indicadores utilizados en el modelo para la determinación diferencial de los modos de vida se detallan en la Tabla 1.

Tabla 1. Variables e indicadores del estudio.

\begin{tabular}{|c|c|}
\hline VARIABLE & INDICADORES \\
\hline \multicolumn{2}{|l|}{$1^{\circ}$ componente: TIPOLOGÍA } \\
\hline Fracción de clase. & Recolector, chambero, clasificador, intermediario, criador de cerdos. \\
\hline Ubicación en el territorio. & $\begin{array}{l}\text { En el basural, frente al basural, los cañonazos, las cumbres alto, el } \\
\text { rocío, las cumbres bajo. }\end{array}$ \\
\hline Ingreso semanal y mensual. & Numérico. \\
\hline Horas y días de trabajo. & Numérico. \\
\hline \multicolumn{2}{|c|}{$2^{\circ}$ componente: PROCESOS DESTRUCTIVOS } \\
\hline & $\begin{array}{l}\text { En intervalo de } 0 \text { a } 17 \text {. Se califica con } 1 \text { punto la presencia de cada } \\
\text { indicador, la suma de indicadores nos da el puntaje total de cada } \\
\text { variable. }\end{array}$ \\
\hline $\begin{array}{l}\text { PDI: Procesos destructivos } \\
\text { físicos. }\end{array}$ & $\begin{array}{l}\text { Ruido fuerte y permanente. Temperaturas extremas. Exposición } \\
\text { directa a radiación solar prolongada. Puntaje } 0-3 \text {. }\end{array}$ \\
\hline PDII a: Contaminación química. & $\begin{array}{l}\text { Polvos irritantes. Biogás. Humo por combustión de residuos. } \\
\text { Residuos fabriles y tóxicos. Puntaje } 0-4 \text {. }\end{array}$ \\
\hline PDII b: Contaminación biológica. & Restos hospitalarios. Fuentes microbianas de contagio. Puntaje 0-2. \\
\hline $\begin{array}{l}\text { PDIII: Derivados de exigencia } \\
\text { laboral física. }\end{array}$ & $\begin{array}{l}\text { Trabajo sedentario. Grandes esfuerzos físicos. Posturas incómodas o } \\
\text { forzadas. Puntaje 0-3. }\end{array}$ \\
\hline $\begin{array}{l}\text { PDIV: Derivados de la } \\
\text { organización del trabajo. }\end{array}$ & $\begin{array}{l}\text { Días por semana, organizados en intervalos }(0=1 \text { a } 4 \text { días, } 1=5 \text { a } 6 \\
\text { días y } 2=7 \text { días }) \text {. } \\
\text { Horas por día que trabaja, organizados en intervalos }(0=1 \text { a } 6 \text { horas, } \\
1=7 \text { a } 9 \text { horas y } 2=10 \text { o más horas }) \text {. Puntaje } 0-4 \text {. }\end{array}$ \\
\hline
\end{tabular}

${ }^{1}$ Cuestionario autoaplicado que permite valorar el sufrimiento mental, y que tiene cuatro subescalas: depresión, ansiedad, relacionamiento social y vulnerabilidad hipocondríaca. Se trata de una prueba de detección con usos asistenciales y epidemiológicos, no sólo orienta el diagnóstico hacia las subescalas sino que discrimina entre ellas y dimensiona sus respectivas intensidades. Consta de 28 ítems, cada uno puntúa de 0 a 1, la puntuación total se valora sobre 28, con cortes de 0-4 para sufrimiento mental leve, 5-9 para moderado y 10 a 28 para severo (Goldberg, 1978).

${ }^{2}$ Es un cuestionario que evalúa el nivel de estresamiento en diferentes dominios del modo de vivir: laboral, consumo, entorno, relaciones cotidianas y afectivas; incorpora variables como el cuidado y crianza de los hijos, las actividades domésticas, la vida de pareja, etc. Pretende correlacionar cómo el estrés psicosocial puede generar situaciones de vulnerabilidad frente a patrones compartidos de exposición. Consta de 28 ítems para varones y 30 para mujeres, cada uno puntúa de 0 a 1 , la puntuación total se valora sobre 28 o 30 , con cortes de 0-4 para estrés laboral leve, 5-16 para moderado y 17 a 28 o 30 para severo (Breilh, 1993; Breilh y col., 2012).

${ }^{3}$ Es una prueba simplificada de tamizaje ("screening") de exposición a toxicidad y detección de signos básicos de afectación psicomotriz por exposición a metano. Consta de 30 preguntas sobre sintomatología de intoxicación aguda, dos pruebas neuromotrices simplificadas y una prueba de memoria. La puntuación total se valora sobre 57, con cortes de 0-19 para neurotoxicidad leve, 20-39 para moderada y 40 a 57 para severa (Breilh y col., 2012). 


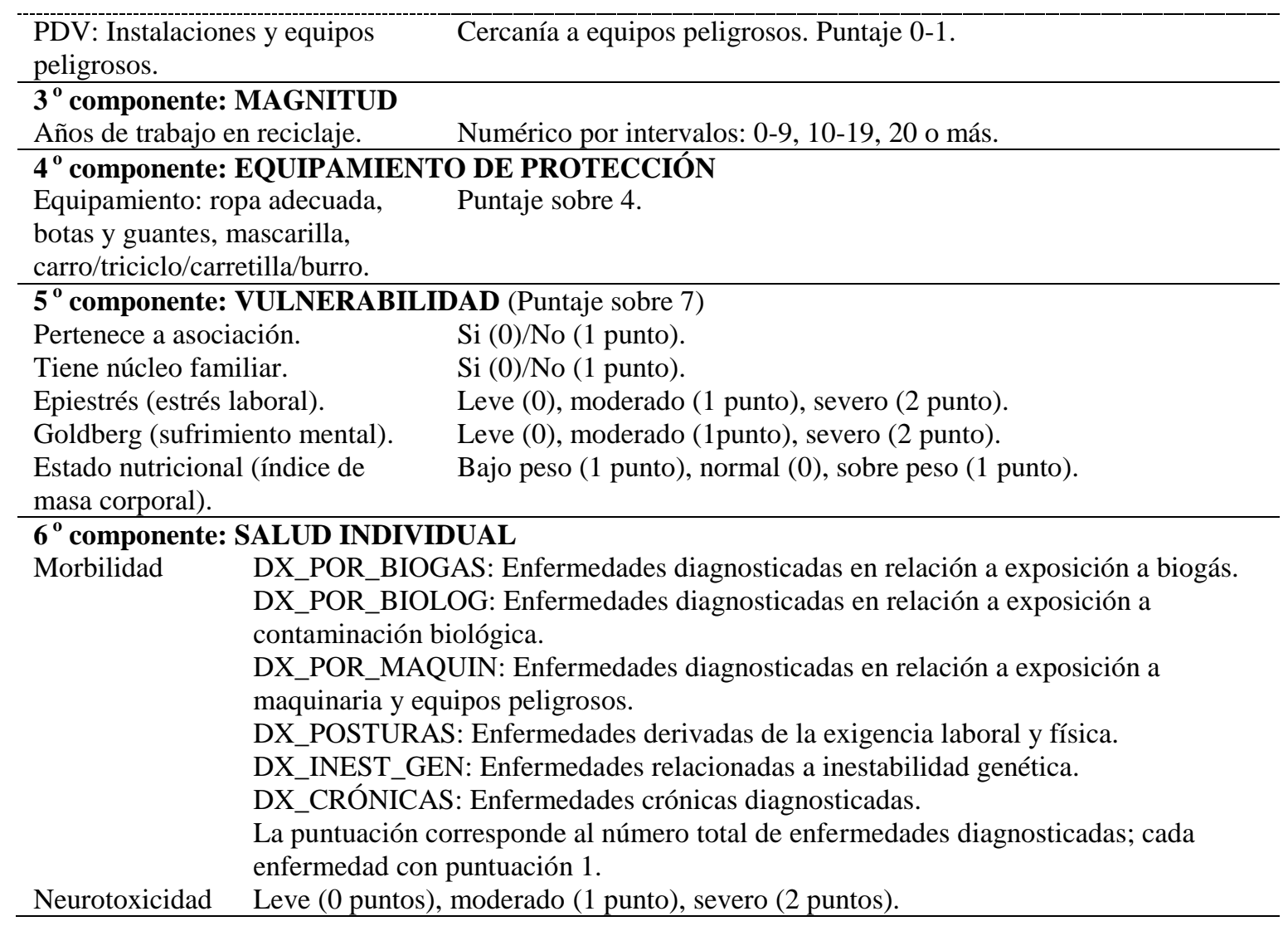

- El primer componente identifica la tipología de los modos de vida en función de la actividad laboral, de la ubicación en el territorio, los ingresos y la jornada de trabajo.

- El segundo componente identifica cinco campos de exposición: físicos, químicos, biológicos, derivados de la exigencia laboral física, derivados de la organización de trabajo, relacionados a instalaciones y equipos peligrosos. En cada campo se definen procesos destructivos también llamados procesos epidemiológicos críticos, la exposición a cada uno de estos procesos puntúa con 1. La puntuación se suma por ítem y la suma de los ítems nos da el puntaje de exposición global sobre 17. Los resultados se organizan en cuatro intervalos: exposición baja, media, alta y muy alta.

- El tercer componente identifica la magnitud de la exposición en función del número de años de trabajo en reciclaje organizado en intervalos. Magnitud 0: de 0 a 8 años; magnitud 1: de 9 a 19 años; magnitud 2: más de 20 años.

- El cuarto componente identifica factores de protección en salud, se determinan 4 ítems de equipamiento de protección, la utilización de cada uno puntúa con 1.

- El quinto componente determina condiciones de vulnerabilidad, para ello identifica la pertenencia a la asociación de recicladores $(\mathrm{No}=1, \mathrm{Si}=0)$, la pertenencia a un núcleo familiar $(\mathrm{No}=1, \mathrm{Si}=0)$, el equivalente de la puntuación de los reactivos Epiestrés (estrés laboral) y Goldberg (sufrimiento mental), ambos en escala de 0-2 (leve, moderado, severo); y finalmente, el estado nutricional determinado desde el índice de masa corporal (bajo peso $=1$, normal $=0 \mathrm{y}$ sobrepeso $=1$ ). Los resultados se expresan con una puntuación total de 0 a 7 .

- El sexto componente valora los impactos en salud. Por un lado, morbilidad diagnosticada por un equipo de médicos generales, cada patología encontrada al momento del estudio puntúa con 1 . En resultados las patologías se presentan agrupadas en función de los procesos destructivos que las desencadenan. Por otro lado, la neurotoxicidad estudiada por el reactivo Pentox, en puntuación de 0 a 57 con cortes de 0 a 3 para intoxicación leve, moderada y severa, respectivamente. 


\subsection{Análisis de datos}

Los datos fueron analizados en el software IBM SPSS Statistics versión 19. Se aplicaron las pruebas estadísticas de $\chi^{2}$ de Pearson, Anova y Análisis de Contingencia para determinar diferencialmente, por cada uno de los tipos laborales determinados (recolectores, chamberos, clasificadores, intermediarios y criadores de cerdos), la exposición (puntuación en procesos destructivos de la salud), la magnitud del impacto (años de exposición), los procesos protectores de la salud, la vulnerabilidad, las patologías diagnosticadas, el nivel de estrés laboral y el sufrimiento mental.

\section{5. Ética}

Todos los recicladores y recicladoras que participaron en el estudio expresaron por escrito su consentimiento informado y autorizaron la utilización anónima de sus testimonios, entrevistas y fotografías. La investigación garantiza el cumplimiento de los principios éticos expresados en la Declaración de Helsinki de la Asociación Médica Mundial (WMA). El protocolo de investigación de la Tesis Doctoral de la cual esta investigación forma parte, fue aprobado por el Comité de Ética de la Universidad Andina Simón Bolívar.

\section{MATERIALES}

\subsection{Universo de estudio}

La investigación fue desarrollada durante los años 2011-2012, con períodos semestrales de trabajo en campo, de veinte días cada uno. En total cuatro momentos, con 3 meses en campo. La población de estudio consiste de 100 familias de recicladores/as informales del vertedero de Portoviejo, 459 personas, 192 mujeres y 267 varones. La Fig. 1 ilustra la distribución espacial de la población.

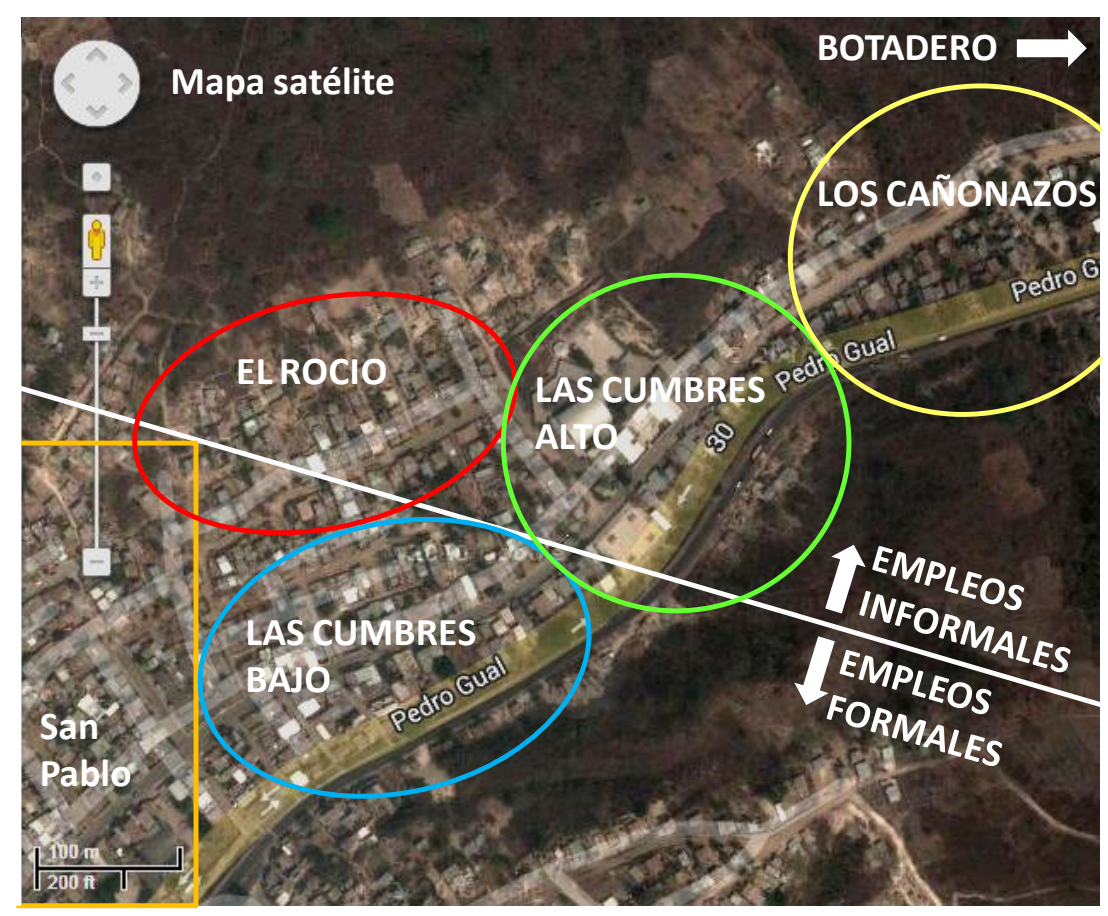

Figura 1. Segregación territorial de empleos formales e informales en la unidad de reciclaje abierto del Cantón Portoviejo por Barrio. 


\subsection{Muestra}

La investigación utiliza el término informal para caracterizar al grupo poblacional de recicladores que trabaja sin vinculación con el Estado, es decir, sin reconocimiento legal, sin contratación, remuneración ni servicios sociales. De las 459 personas vinculadas al vertedero a cielo abierto de Portoviejo, son 150 personas quienes trabajan en cualquiera de las fases de la economía informal del reciclaje y por ende cumplen los criterios de selección por lo que fueron retenidos para el análisis. Los demás corresponden a niños, niñas, adolescentes y ancianos que no realizan actividades de reciclaje y por tanto fueron excluidos de la muestra.

\subsection{Caracterización de la muestra}

El vertedero a cielo abierto de Portoviejo se ubica al término de la Parroquia urbano marginal San Pablo, en ésta, se encuentran asentamientos poblacionales informales conocidos como barrios las Cumbres, el Rocío y los Cañonazos. Las actividades productivas de estos territorios se articulan esencialmente alrededor de la recuperación informal de basura. Existen varios tipos de labores y roles, cada uno de ellos inserto en una estructura jerárquica con determinadas condiciones de remuneración y reconocimiento.

Varios estudios han propuesto distintas tipologías de reciclaje informal, la mayoría identifican al menos seis categorías de recicladores informales: colector de residuos domésticos (recogen material directamente de domicilios e instituciones), recolectores urbanos (recogen el material mezclado de las calles), compradores itinerantes, tripulación municipal de recolección (las materias primas secundarias son recuperados y separados de los vehículos de transporte de RSU a los sitios de disposición), recolectores trabajando en vertederos e intermediarios (Ezeah y col., 2013; Paul y col., 2012; Wilson y col., 2006).

Nuestra investigación reconoce actores formales e informales en toda la cadena de la economía de reciclaje (Zia y col., 2008 en Ezeah y col., 2013; Gutberlet, 2008). Específicamente en nuestro caso de estudio identificamos la siguiente tipología estructurada por fase de la gestión de residuos:

1. Barrido y limpieza

a. Empleados municipales formales

b. Recolectores urbanos informales

2. Recolección de residuos

a. Empleados municipales formales ${ }^{4}$

b. Chamberos ${ }^{5}$

3. Disposición final: todos los trabajadores en esta fase pertenecen a la economía informal

a. Recolector de residuos orgánicos para alimentación de animales menores (crianza de cerdos)

b. Recolector de residuos inorgánicos

c. Clasificador de residuos

d. Intermediarios

e. Empleados de intermediarios

4. Comercializadores (actividades formales)

De todos estos actores identificados, nuestra investigación limita intencionalmente el estudio a aquellos de la economía informal del reciclaje, estructurados en la siguiente tipología: recolectores de residuos, criadores de animales, chamberos, clasificadores e intermediarios (con sus empleados).

Tal como lo ilustra la Fig. 1, construida como parte de un proceso de cartografía social participativa, si analizamos territorialmente la división entre las categorías formal/legal e informal/ilegal, podemos mirar que la presencia de trabajadores municipales formales disminuye a medida que nos distanciamos del centro urbano y nos acercamos al botadero. La mayoría de los

\footnotetext{
${ }^{4}$ Algunos empleados municipales de la recolección de residuos realizan adicionalmente actividades informales de recuperación de residuos. Con ello además de percibir su remuneración formal, tienen ingresos adicionales de actividades de reciclaje.

${ }^{5}$ Homólogo al tipo: tripulación municipal de recolección, pero en este caso se trata de una actividad informal, personas sin vinculación municipal recuperan materia prima desde las volquetas recolectoras.
} 
empleados públicos se encuentran en la zona baja del San Pablo y en la zona baja del Barrio las Cumbres. En los Barrios El Rocío, Las Cumbres alto, Los Cañonazos, en el Basural a Cielo Abierto y Frente al Basural (suburbios de mayor marginación), no se reportan empleos formales.

Quizás ésta sea una de las evidencias más contundentes de segregación sociohistórica de territorios afectados por procesos socioambientales destructivos que además pone en evidencia la situación de "encadenamiento laboral" (Solíz, 2013) en la que viven comunidades afectadas por conflictos socioambientales. Utilizamos la categoría encadenamiento laboral, para describir el fenómeno en el que la actividad laboral es al mismo tiempo el proceso protector y el proceso destructivo de la salud. En este caso, el basural a cielo abierto es provisor absoluto del sustento económico familiar (proceso protector), y al mismo tiempo determina los patrones de exposición y vulnerabilidad (proceso destructivo). Adicionalmente, la situación de encadenamiento condiciona toda actividad productiva al proceso destructivo, en estos barrios nadie siembra, ni produce; si el vertedero desaparece, la población desaparece.

Como ya mencionamos, el estudio ha definido como muestra intencional a toda la población de recicladores informales, la Fig. 2 ilustra la distribución de la muestra por tipología laboral, sexo y edad.

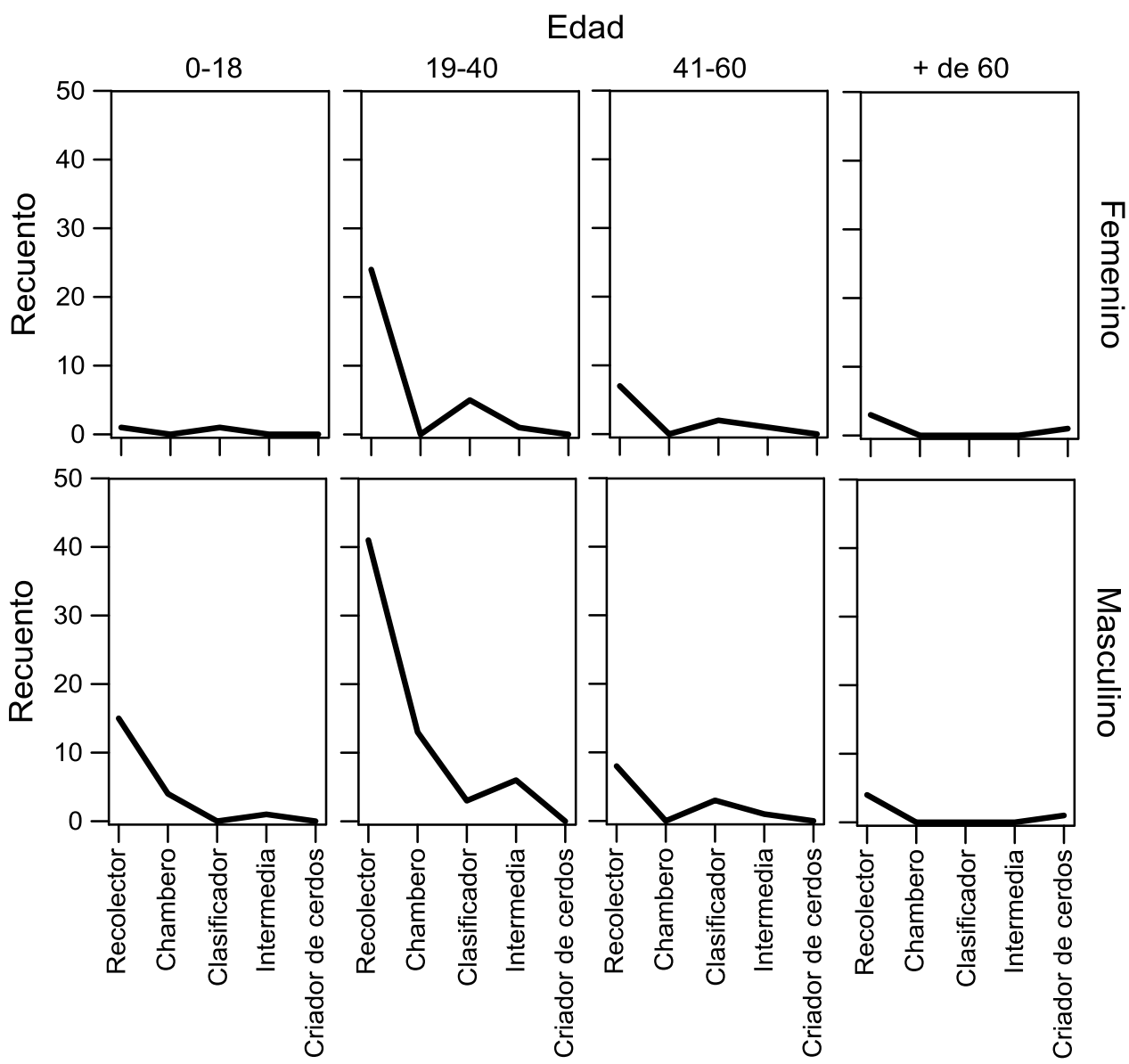

Figura 2. Distribución de la muestra por actividad laboral, género y edad ( $(\mathrm{N}$ : recolector $=106$; chambero $=17$; clasificador $=15$; intermediario $=10$; criador cerdos $=2 ;$ total $=150)$.

Según se observa, existe un número mayoritario de recolectores, seguido por chamberos y clasificadores, mientras intermediarios y criadores de cerdos aparecen en menor proporción, los criadores de cerdos equivalen a recolectores de material orgánico por lo que podrían considerarse parte de este grupo, sin embargo, dos adultos mayores participantes en esta investigación rehusaron a reconocerse como recolectores y se autodefinieron como criadores de animales. La investigadora 
respetó este criterio. La estructura de la muestra determina la cadena de explotación, con una amplia base de trabajadores recolectores y un limitado pico de intermediarios. En relación a las edades, el grupo de 19 a 40 años es el más numeroso. Finalmente, de acuerdo al género, el 32\% de la población total es femenina y el $68 \%$ restante masculino. Resulta interesante que del $32 \%$ de mujeres trabajando en reciclaje, la gran mayoría, el $25 \%$, trabaja en recolección. Por otro lado, podemos mirar que no existen mujeres trabajando como chamberas, y nada más un $1 \%$ de ellas se dedica a la intermediación. Estos datos evidencian la discriminación de género dado a que las mujeres realizan predominantemente los trabajos de mayor exposición y menor remuneración.

\section{RESULTADOS}

\subsection{Caracterización de la tipología de actores del reciclaje informal}

Análisis de la muestra intencional revela que los recicladores informales se pueden agrupar en las siguientes clases:

- Recolector: Recoge el material orgánico e inorgánico directo del vertedero, lo selecciona y vende al intermediario o a sus empleados. El $71 \%$ de todos los recicladores entran en esta categoría (15\% mujeres, $46 \%$ varones). La edad promedio de este grupo es de 32,13 años y el ingreso promedio mensual es de 203 USD.

- Chambero: Recupera material inorgánico directo de las volquetas recolectoras durante los recorridos y lo vende a intermediarios o a sus empleados. El $11 \%$ de los recicladores trabaja como chambero ( $0 \%$ mujeres, $11 \%$ varones). La edad promedio de este grupo es de 23 años y el ingreso promedio mensual es de 158 USD.

- Clasificador: Pueden ser de dos tipos, los que trabajan con los recolectores, en estos casos se trata de una división familiar del trabajo, el varón recolecta, la mujer limpia, organiza y clasifica; o una situación homóloga pero entre padres e hijos. El segundo tipo de clasificador es el que trabaja directamente para el intermediario en su centro de acopio. En total, los clasificadores representan el $10 \%$ de los recicladores (5\% mujeres, $5 \%$ varones). Su ingreso mensual promedio es de 270 USD y la edad promedio de este grupo es de 34,33 años.

- Intermediarios: Se encargan de recibir el material clasificado, pesarlo, empacarlo y pagar a los recicladores. Funcionan como un banco comunitario, que otorga créditos y anticipos, que define el salario en función de los valores asignados a los distintos materiales. Representan el $6 \%$ del total (1\% mujeres, $5 \%$ varones), su edad promedio es de 32,90 años. El ingreso mensual promedio es de 447 USD.

- Criadores de animales: Se dedican exclusivamente a recolectar materiales orgánicos para la alimentación de sus animales. Solamente un matrimonio de adultos mayores que viven dentro del basural se definieron como criadores de cerdos. El ingreso promedio es de 203 USD y la edad promedio de 60 años.

- Comercializadores: Son figuras ausentes, son las empresas a las que intermediarios entregan el material. Nunca se presentan en el vertedero ni en el barrio.

\subsection{Perfiles epidemiológicos: Exposición, vulnerabilidad y salud}

La determinación de los modos de vida relacionó la variable fracción de clase (tipología en la cadena de reciclaje) con barrio en el que vive, ingreso mensual en dólares, horas de trabajo al día y días de trabajo a la semana. El análisis de Anova develó un nivel de significancia alto para ingreso $(0,000)$ y bajo para días y horas de trabajo $(0,146$ y 0,162$)$ respectivamente. Existe un nivel salarial similar entre recolectores (203 USD), chamberos (158 USD) y criadores de cerdos (203 USD), a éstos le siguen los clasificadores (270 USD); y finalmente, encontramos a los intermediarios (447 USD). En promedio, los recolectores trabajan más días y horas que todos los demás tipos estudiados; sin embargo, no se trata de diferencias significativas. A nivel general todos los grupos trabajan entre 5 y 6 días a la semana, 6 horas diarias. Existen sin embargo picos en los valores mínimos y máximos, siendo los 
intermediarios, chamberos y criadores de cerdos quienes aparecen en los valores mínimos con puntuaciones de 2,5 y 3 horas diarias; mientras los recolectores puntúan en los valores máximos con hasta 14 horas de trabajo. Con respecto a la organización barrial, realizamos un análisis de contingencia, la prueba de $\chi^{2}$ de Pearson estableció una alta significancia $(0,00)$. Las viviendas ubicadas dentro del Basural a Cielo Abierto corresponden en un $83 \%$ a recolectores, frente al Basural y en el barrio los Cañonazos los porcentajes de recolectores se mantienen en un $70 \%$, mientras que en los barrios más distantes al basural y por ende con menor nivel de exposición (cumbres alto y bajo) el porcentaje de recicladores disminuye a $40 \%$ e incrementa el de clasificadores e intermediarios. Estos datos corroboran nuestra afirmación en torno a la segregación del espacio territorial, los actores informales de la economía del reciclaje son los que viven más cerca o dentro del vertedero.

\subsubsection{Exposición}

El análisis de contingencia entre la tipología establecida en función de la actividad laboral y el nivel de exposición a los cinco grupos de procesos destructivos detallados en el diseño de variables, presenta una alta significancia $(0,000)$. El puntaje máximo de exposición a procesos epidemiológicos críticos es de 17 puntos, los resultados se organizan en cuatro niveles de exposición: baja, media, alta y muy alta. La sección superior de la Fig. 3 ilustra el número de personas por tipología y nivel de exposición, y la sección baja de la Fig. 3, ilustra el porcentaje de los actores que están puntuando en cada nivel de exposición a procesos destructivos de la salud.

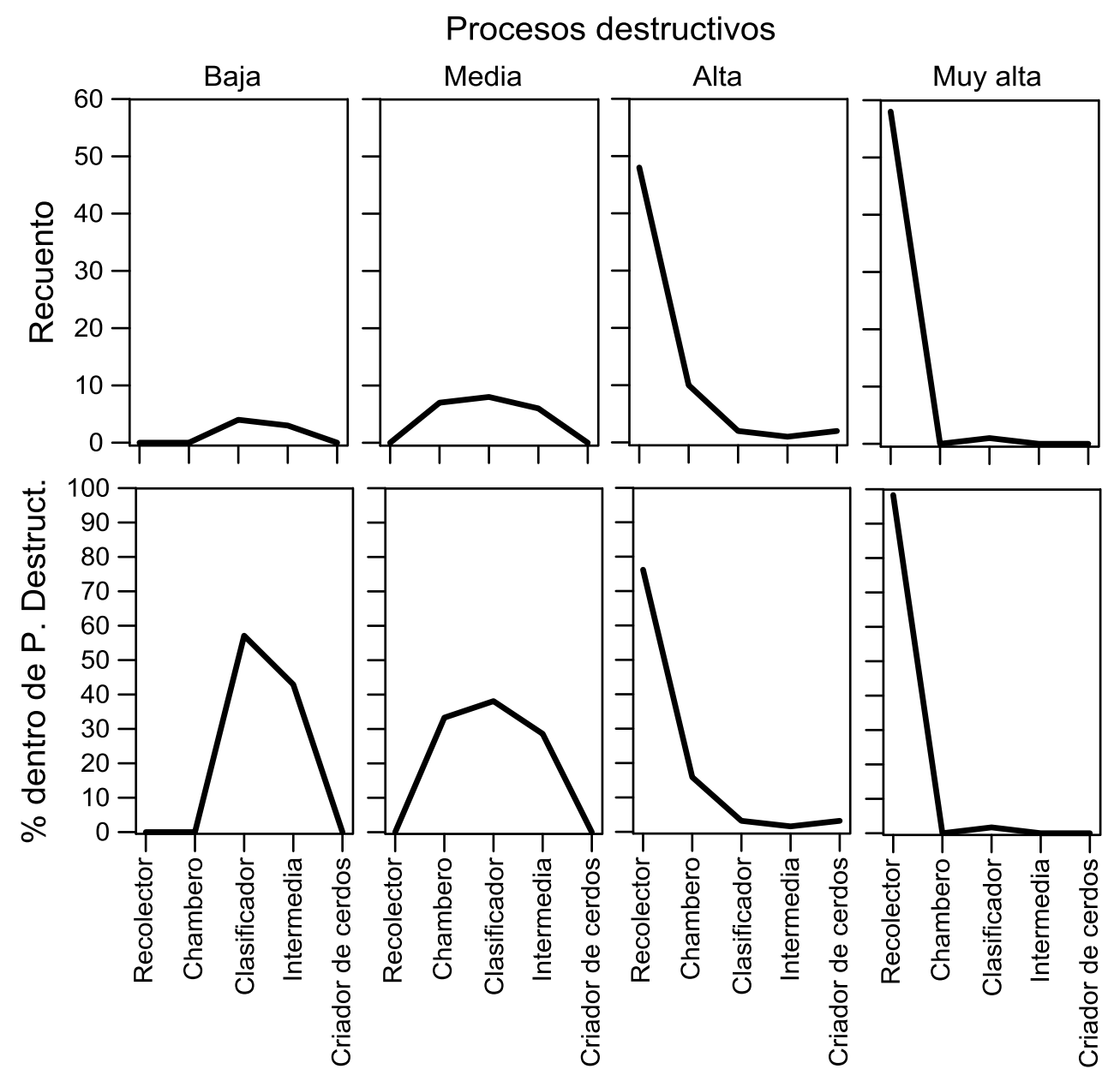

Figura 3. Análisis de contingencia: tipología laboral y procesos destructivos (N: recolector $=106$; chambero $=17$; clasificador $=15$; intermediario $=10$; criador cerdos $=2$; total $=150$ ) . 
Tal como se evidencia, en exposición baja identificamos a clasificadores e intermediarios. En el nivel de exposición media encontramos que a estos dos grupos se suman los chamberos. La exposición alta es mayoritariamente presente en recolectores, con un menor porcentaje en chamberos. Finalmente el nivel de exposición muy alta corresponde en el 98,3\% de los casos a recolectores. Por otro lado, el análisis de medias, establece un promedio de 13,82 procesos destructivos en recolectores, 10,29 en chamberos, 7,13 en clasificadores, 6,10 en intermediarios y 11 en criadores de cerdos. En conclusión, los recolectores son el grupo laboral más expuesto doblando la puntuación de intermediarios como tipología de menor exposición.

\section{$\underline{\text { Magnitud }}$}

En relación a la magnitud de la exposición, el análisis de contingencia entre años de trabajo en reciclaje (magnitud) y tipo de trabajo no es significativo. Si realizamos un análisis de medias, determinamos un promedio de 12 años para recolector, 8 para chamberos, 15 para clasificadores, 10 para intermediarios y 35 para criadores de cerdos.

\section{Procesos protectores}

En el análisis de contingencia entre procesos protectores y tipología laboral, puntúa como baja significancia en la prueba del $\chi^{2}$ de Pearson en tanto en ninguna de las tipologías se reporta la utilización de equipo de protección.

\subsubsection{Vulnerabilidad}

El análisis de vulnerabilidad incluye la pertenencia a la asociación de recicladores, la pertenencia a un núcleo familiar, el equivalente de la puntuación de los reactivos Epiestrés y Goldberg y finalmente el estado nutricional determinado desde el índice de masa corporal. Los resultados se expresan con una puntuación total de 0 a 7. La relación entre tipología laboral y vulnerabilidad, ver la Fig. 4, tiene un coeficiente de contingencia significativo 0,020. En esta figura se encuentra el número de personas por tipología y nivel de vulnerabilidad (sección superior en la Fig. 4), y el porcentaje dentro de vulnerabilidad, que devela porcentualmente los actores que están puntuando en cada nivel (sección bajo en la Fig. 4).

La Fig. 4 ilustra que la tipología correspondiente a recolectores presenta predominantemente niveles de vulnerabilidad moderada y alta; por el contrario, los intermediarios tienen un pico en vulnerabilidad leve. Del total de trabajadores que presentan alta vulnerabilidad, el $70 \%$ son recolectores.

\subsubsection{Salud}

\section{Morbilidad}

El estudio del estado de salud de la población se realizó mediante el examen clínico de cada uno de los recicladores/as. Al realizar un análisis de medias entre la puntuación total de los procesos destructivos reportados y la totalidad de las enfermedades diagnosticadas, encontramos un elevado coeficiente de significancia $(0,000)$ siendo los recolectores, seguido de chamberos y criadores de cerdos, quienes tienen mayor número promedio de procesos destructivos y por ende de patologías diagnosticadas.

Por otro lado, las patologías diagnosticadas se agruparon de acuerdo al proceso destructivo al que se vincula su etiología. Con excepción de las enfermedades crónicas, el grupo de recolectores tiene una media mayor de patologías diagnosticadas. El análisis Anova establece coeficientes significativos para la relación, tipología-enfermedades de transmisión biológica, tipología- enfermedades ocasionadas por maquinaria y tipología-enfermedades crónicas, con valores de 0,$009 ; 0,003$ y 0,000 respectivamente. A continuación exponemos la Fig. 5, que nos da cuenta del perfil de morbilidad de los trabajadores recicladores en función del tipo de actividad laboral que realizan. 


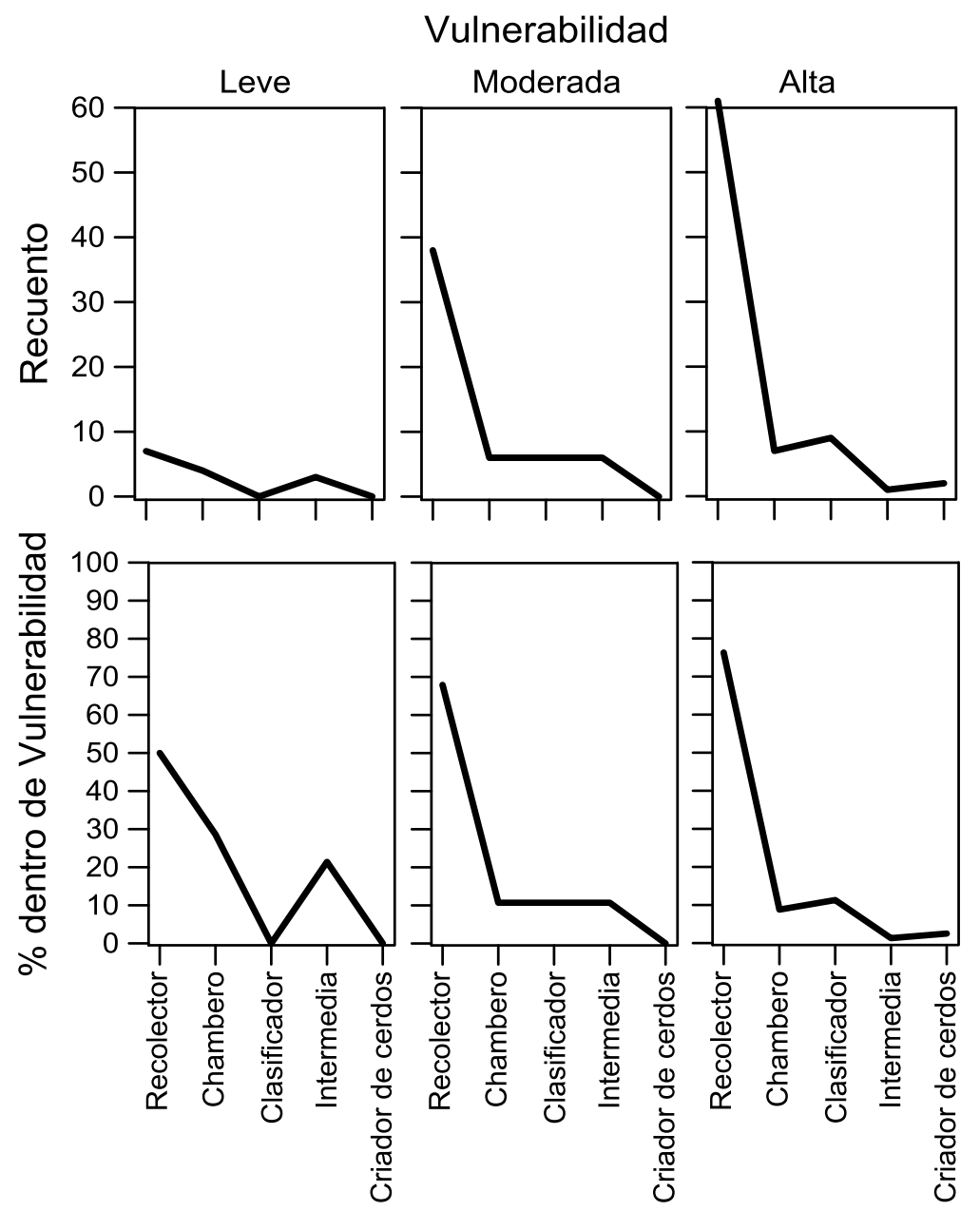

Figura 4. Análisis de contingencia: tipología laboral y vulnerabilidad (N: recolector $=106$; chambero $=17$; clasificador $=15 ;$ intermediario $=10$; criador cerdos $=2 ;$ total $=150$ )

Como podemos analizar, recolectores, chamberos y criadores de cerdos son quienes presentan una media más elevada de enfermedades ocasionadas por la exposición a biogás, siendo los recolectores quienes puntúan más alto en valores máximos, presentando hasta 4 enfermedades ocasionadas por contaminación química. En relación a patologías producidas por exposición biológica y maquinaria, recolectores, seguidos de chamberos y clasificadores son quienes tienen una media mayor de enfermedades diagnosticadas al momento del estudio. En relación a enfermedades ocasionadas por posturas inadecuadas, observamos en valores máximos un pico de hasta tres enfermedades en la tipología correspondiente a recolectores. La presencia de inestabilidad genética tiene una media regular en las cinco tipologías con un pico en valores máximos para el caso de recolectores. Es únicamente en el caso de enfermedades crónicas que encontramos a los intermediarios con una media y con valores máximos significativamente más elevados que los demás tipos de estudio.

Si nos detenemos en el análisis de la tipología de patologías diagnosticadas por cada campo, en las enfermedades transmitidas por contaminación química (biogás) priman las alergias respiratorias, mareos, disnea, y problemas oculares como irritación, infecciones y pterigium. En el caso de enfermedades transmitidas por contaminación biológica, encontramos mayoritariamente infecciones gastrointestinales, infecciones de la piel, micosis y enfermedades infectocontagiosas. En relación a las patologías ocasionadas por posturas inadecuadas o grandes esfuerzos físicos, si bien encontramos frecuencias medias homogéneas en todas las tipologías, mientras las patologías diagnosticadas en recolectores están directamente relacionadas con la postura y los grandes esfuerzos; las patologías en clasificadores e intermediarios se relaciona más bien con el sedentarismo. En el caso de las 
enfermedades relacionadas a maquinaria, los más afectados son recolectores quienes presentan hipoacusia, dolores de oído y accidentes.

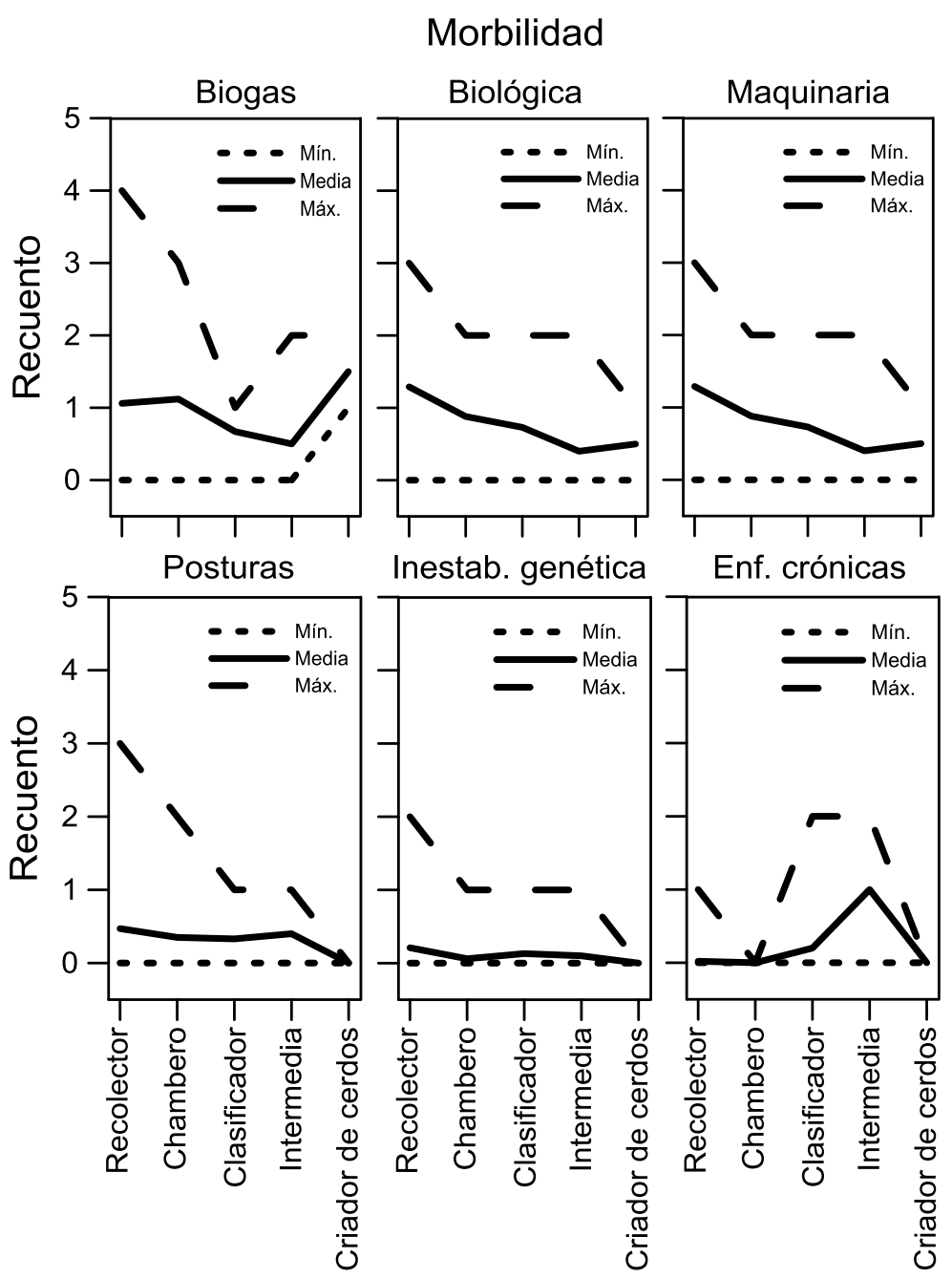

Figura $5^{6}$. Análisis de medias: tipología y morbilidad $(\mathrm{N}$ : recolector $=106$; chambero $=17$; clasificador $=15$; intermediario $=10$; criador de $\operatorname{cerdos}=2$; total $=150$ ).

En cuanto a enfermedades crónicas, el $80 \%$ de diagnósticos corresponde a intermediarios. Las principales reportadas fueron hipertensión, hipercolesterolemia y diabetes, por ello, consideramos oportuno correlacionarlas con el índice de masa corporal (IMC). La prueba del $\chi^{2}$ de Pearson estableció para esta relación una alta significancia, el $90 \%$ de los intermediarios presentan sobrepeso y el $60 \%$ de ellos presentan enfermedades crónicas (40\% más de 1 enfermedad crónica).

Finalmente, realizamos un análisis de contingencia entre enfermedades relacionadas a inestabilidad genética, magnitud del impacto (años de trabajo), días y horas de trabajo encontrando una baja significancia para las tres variables con unos valores de 0,$311 ; 0,368 ; 0,129$ respectivamente.

$\underline{\text { Neurotoxicidad }}$

\footnotetext{
${ }^{6}$ DX_POR_BIOGAS: Enfermedades en relación a exposición a biogás.

DX_POR_BIOLOG: Enfermedades en relación a exposición a contaminación biológica.

DX_POR_MAQUIN: Enfermedades en relación a exposición a maquinaria y equipos peligrosos.

DX_POSTURAS: Enfermedades derivadas de la exigencia laboral y física.

DX_INEST_GEN: Enfermedades relacionadas a inestabilidad genética.

DX_CRÓNICAS: Enfermedades crónicas.
} 
En relación a la neurotoxicidad, el análisis de medias que compara la puntuación por tipología tiene una alta significancia y determina una media de 27,49 para recolectores, 18,29 para chamberos, 20,33 para clasificadores, 15,30 para intermediarios y 49,50 para criadores de cerdos. Evidentemente, quienes trabajan directamente sobre el vertedero (recolectores) tienen mayores niveles de neurotoxicidad. En el caso de los criadores de cerdos, debemos recordar que se trata de dos ancianos que viven desde hace cuarenta años dentro del basural pero que no se reconocen como recolectores en tanto únicamente recogen material orgánico para sus cerdos. De la misma manera, en el análisis de contingencia, la prueba del $\chi^{2}$ de Pearson establece una alta significancia $(0,000)$. El $93 \%$ de los casos de neurotoxicidad elevada corresponde a recolectores y el $7 \%$ a criadores de cerdos, mientras tanto, el $90 \%$ de los intermediarios presenta baja neurotoxicidad.

\section{Estrés laboral}

Se realizó un análisis de contingencia entre los tipos definidos (recolector, chambero, clasificador, intermediario y criador de cerdos) con los resultados de la aplicación del test Epiestrés. La prueba de $\chi^{2}$ de Pearson determina una alta significancia $(0,043)$. El 84,4\% de los casos de estrés severo y el 66,7 de casos de estrés moderado corresponden a recolectores. Si realizamos el análisis además por género son las mujeres recolectoras quienes presentan mayores puntajes. El $67 \%$ de mujeres recolectoras presenta un nivel severo de estrés laboral, en comparación con el 18,8\% de varones dedicados a la misma actividad.

\section{Sufrimiento mental}

El test de Goldberg fue el reactivo utilizado para realizar un screening (tamizaje) del estado de salud mental de la población recicladora. El análisis de contingencia entre tipología laboral y el Test de Goldberg tiene una significancia alta $(0,001)$. El 81,2\% de los casos de sufrimiento mental severo corresponde a población recolectora. En relación al género, el 70,8\% de las mujeres puntúa en sufrimiento mental severo, $81 \%$ de ellas, son recolectoras. En el caso de los varones los porcentajes de sufrimiento mental severo descienden a $34,7 \%$.

\subsection{Determinación fenotípica del perfil epidemiológico}

Partiendo de los análisis anteriores, la Tabla 2 determina los perfiles epidemiológicos y su estructura fenotípica, para cada tipo laboral. En cada fila encontramos la tipología laboral (recolectores, chamberos, clasificadores, intermediarios y criadores de cerdos), en la primera columna tenemos la descripción de la representación porcentual de cada tipo dentro de la muestra de estudio, de su composición por género, de la media de edad y de los ingresos mensuales. La segunda columna determina patrones diferenciales de exposición, definiendo la media de procesos destructivos identificados por tipo así como describiéndolos. En la tercera columna exponemos el perfil de morbilidad, con la media de patologías diagnosticadas al momento de estudio y la descripción de las mismas. La cuarta columna propone la diferenciación del fenotipo en función de la descripción de la estructura ósea y de la musculatura, del índice de masa corporal y las características de la piel. Finalmente, la quinta columna propone una visión gráfica del fenotipo.

\section{DISCUSIÓN Y CONCLUSIONES}

La basura como noción subjetiva, puede concebirse como un riesgo para el medio ambiente y por ende para la salud, como un problema estético o como una fuente de ingresos (Sembiring y Nitivattananon, 2010). Para los recicladores informales, la basura es su actividad laboral y fuente de supervivencia. Existen muchas denominaciones en los diferentes países para referirse a los actores de la economía del reciclaje informal: pepenadores, cartoneros u buscabotes en México; basuriegos, cartoneros, traperos y chatarreros en Colombia; buzos en Costa Rica y Cuba; cirujas en Argentina; y chamberos en Ecuador (Medina y Dows, 2000; Berthier, 2003). En todos los casos, se trata de minorías excluidas y marginadas sobre las cuáles se construyen múltiples imaginarios, frecuentemente son percibidos como 
gente sucia, peligrosa, que desordena el espacio público por lo que, con frecuencia, ven obstaculizadas sus actividades de recolección (Wilson y col., 2006).

Múltiples estudios coinciden en que el reciclaje es una actividad que data de muchos siglos, y que luego de la crisis monetaria y económica global -finales de los 90`s. Cada vez más, sectores urbano marginales se vieron inmersos en estas actividades (Sembiring y Nitivattananon, 2010; Medina, 2003). Así lo comprueba el estudio de Anastasia (2007), Dewi (2007), Hadiana, 2006 en Gutberlet y col. (2006), que afirma que la mayoría de recicladores entrevistados al 2007, llevaban menos de 10 años trabajando en reciclaje. En nuestra investigación el promedio de años de reciclaje es de 12 años, con valores mínimos de 1 año y máximos de 45 años. Estos datos confirman nuestra tesis sobre la intensificación de actividades de reciclaje durante la agudización de las políticas neoliberales.

En los países en vías de desarrollo, el reciclaje siempre ha sido una estrategia de vida para los más pobres y excluidos en la ausencia de un sistema de seguridad social (Berthier, 2003), y actualmente es la principal actividad de las personas socialmente excluidas. Ali (1999) señala que el reciclaje informal aumentaría en los períodos de crisis económica, con altos índices de desempleo y pobreza. El reciclaje aparece entonces como una respuesta de adaptación a la escasez local de recursos.

Frente a este fenómeno creciente, surgen una serie de publicaciones que cada vez más, visibilizan la importancia ambiental y económica derivada de la economía informal del reciclaje y con ello surge la urgencia de por un lado develar y atender los impactos en salud ocasionados por la inadecuada gestión de residuos en recicladores y comunidades vecinas a sistemas de disposición final y por otro, fortalecer procesos asociativos para la inclusión de este sector en las políticas públicas de gestión integral de residuos.

Además, existen numerosos estudios sobre los impactos en salud laboral de recicladores/as (Bonfanti, 2004; Silva y col., 2002; Rego, 2002; Ferreira y Anjos, 2001), todos concuerdan en que este trabajo genera distintos niveles y condiciones de exposición. Si bien los criterios de organización de los procesos destructivos varían en cada estudio. La mayoría reconoce al menos los siguientes agentes: físicos, biológicos, químicos, accidentes y riesgos laborales (Ferreira y Anjos, 2001). Otros trabajos (Wilson y col., 2006) identifican factores de riesgo en relación a: composición de los residuos, descomposición de residuos orgánicos, la manipulación, el procesamiento y la disposición de los residuos.

Estos agentes o niveles de exposición se expresan en la contaminación del agua ocasionada por la producción de lixiviados, la contaminación del suelo con químicos y microorganismos patógenos; la generación de biogás (compuesto esencialmente de metano, dióxido de carbono y óxido de azufre); las explosiones e incendios generados por la putrefacción de la basura, los accidentes y riesgos ocupacionales (aplastamiento, enterramiento, cortaduras) y finalmente la exposición directa a residuos hospitalarios e industriales (Gutberlet, 2008).

En relación a los impactos en salud, existe acuerdo sobre las patologías presentes en población recicladora, en tanto están directamente vinculadas con los agentes de exposición. De hecho, este grupo poblacional ha sido reconocido como el de mayor exposición biológica, física, química y social que trabajadores de cualquier otra actividad (Wilson y col., 2006; Gutberlet y Baeder, 2008). Por otro lado, y en coincidencia con los resultados de nuestro estudio, investigaciones refieren que los riesgos de salud se ven incrementados por la no utilización de equipos de protección como guantes, botas y mascarillas (Wilson y col., 2006; Monirozzaman y col., 2011) por lo que se encuentran en contacto directo con contaminantes biológicos, químicos tóxicos y materiales corto punzantes (Wilson y col., 2006; Ezeah y col., 2013). Especialmente el inadecuado manejo de los residuos hospitalarios -en el caso de Portoviejo se recolectan y disponen mezclados con los residuos domiciliarios- incrementan el riesgo de contagio de enfermedades transmisibles (Wilson y col., 2006; Damghani y col., 2008).

Los impactos en salud, van sin embargo más allá de la población recicladora y se extienden a comunidades vecinas, primordialmente niños/as mujeres y ancianos/as quienes son altamente vulnerables a enfermedades como dengue, lesmaniasis, diarrea, tifoidea, cólera, malaria y problemas 
Tabla 2. Definición fenotípica del perfil epidemiológico.

\begin{tabular}{|c|c|c|c|c|}
\hline $\begin{array}{l}\text { Tipología (\% del total de } \\
\text { recicladores informales). }\end{array}$ & $\begin{array}{l}\text { Patrones de exposición } \\
\text { diferencial (Puntaje de los } \\
\text { procesos destructivos sobre } \\
\text { un total de 17). }\end{array}$ & $\begin{array}{l}\text { Perfil de morbilidad (Media } \\
\text { de patologías diagnosticadas } \\
\text { al momento del examen } \\
\text { físico). }\end{array}$ & $\begin{array}{l}\text { Diferenciación en el } \\
\text { fenotipo }^{7}, \mathrm{IMC}^{8}, \mathrm{Piel}^{9} .\end{array}$ & $\begin{array}{l}\text { Expresión gráfica } \\
\text { fenotipo. }\end{array}$ \\
\hline $\begin{array}{l}\text { Recolectores }(71 \%) . \\
15 \% \text { mujeres. } \\
46 \% \text { varones. } \\
\text { Edad media: } 32,13 \text { años. } \\
\text { Ingreso medio: } 203 \text { USD. }\end{array}$ & $\begin{array}{l}\text { Media de exposición } \\
(13,82) \text {. } \\
\text { Procesos destructivos: } \\
\text { físicos, químicos, } \\
\text { biológicos, organización del } \\
\text { trabajo, cercanía equipos } \\
\text { peligrosos. Trabajo directo } \\
\text { sobre el vertedero sin } \\
\text { equipo de protección. }\end{array}$ & $\begin{array}{l}\text { Media de patologías } \\
\text { diagnosticadas }(3,23) \text {. } \\
\text { Respiratorias, digestivas, } \\
\text { vías urinarias, } \\
\text { infectocontagiosas, } \\
\text { dérmicas, oculares, del oído, } \\
\text { alergias, cefaleas, mareos, } \\
\text { disnea, malformaciones } \\
\text { congénitas, síndromes, } \\
\text { discapacidades y abortos. } \\
\text { Media de estrés laboral: } \\
\text { 14,19 (severo). Media de } \\
\text { sufrimiento mental: } 23,79 \\
\text { (severo). }\end{array}$ & $\begin{array}{l}\text { Media de IMC }(22,20) \text {. } \\
\text { El } 100 \% \text { de diagnósticos de } \\
\text { bajo peso se ubican en este } \\
\text { grupo. } \\
\text { Fenotipo longilíneo, } \\
\text { musculatura desarrollada, } \\
\text { piel deteriorada, presencia } \\
\text { de amplias áreas de micosis, } \\
\text { coloración muy oscura. }\end{array}$ & \\
\hline $\begin{array}{l}\text { Chamberos }(11 \%) \text {. } \\
0 \% \text { mujeres. } \\
11 \% \text { varones. } \\
\text { Edad media: } 23 \text { años. } \\
\text { Ingreso medio: } 158 \text { USD. }\end{array}$ & $\begin{array}{l}\text { Media de exposición } \\
(10,29) \text {. } \\
\text { Procesos destructivos } \\
\text { físicos, químicos, } \\
\text { biológicos, posturas } \\
\text { forzadas, cercanía equipos } \\
\text { peligrosos. Trabajo directo } \\
\text { sobre volquetas recolectoras } \\
\text { sin equipo de protección. }\end{array}$ & $\begin{array}{l}\text { Media de patologías } \\
\text { diagnosticadas }(2,47) \text {. } \\
\text { Respiratorias, digestivas, } \\
\text { infectocontagiosas, } \\
\text { dérmicas, oculares, alergias, } \\
\text { cefaleas, mareos. } \\
\text { Media de estrés laboral: } 9 \\
\text { (moderado). Media de } \\
\text { sufrimiento mental: } 15,35 \\
\text { (severo). }\end{array}$ & $\begin{array}{l}\text { Media IMC }(24,47) \text {. } \\
\text { Más jóvenes, pequeños, } \\
\text { delgados, en su mayoría } \\
\text { varones. Musculatura menos } \\
\text { desarrollada que } \\
\text { recolectores. Piel } \\
\text { deteriorada, presencia de } \\
\text { amplias áreas de micosis, } \\
\text { coloración muy oscura. }\end{array}$ & \\
\hline
\end{tabular}

${ }^{7}$ La caracterización del fenotipo se construye en base del estudio etnográfico, los períodos de acompañamiento y el análisis de las historias de salud individual.

8 El índice de masa corporal fue obtenido mediante la ecuación (peso en kg por estatura en $\mathrm{m}^{2}$ ). En cada uno de los tipos laborales identificados realizamos un análisis de media, mediana y moda. El valor seleccionado para esta tabla de resultados fue la media.

9 Para el análisis de la piel, un grupo de médicos especialistas en dermatología evaluó a los 150 actores de la economía del reciclaje informal. 
Tabla 2. Definición fenotípica del perfil epidemiológico (continuación)

\section{Clasificador (10\%).}

$5 \%$ mujeres.

$5 \%$ varones.

Edad media: 34,33 años.

Ingreso medio: 270 USD
Media de exposición $(7,13)$. Media de patologías

Procesos destructivos químicos, biológicos, derivados de la exigencia laboral, sedentarismo, posturas forzadas, trabajo sin equipo de protección.

hipertensión,

hipercolesterolemia, diagnosticadas $(2,13)$.

Infecciones respiratorias,

digestivas, vías urinarias,

dérmicas, oculares, cefaleas,

abortos, malformaciones

Media de estrés laboral:

10,80 (severo). Media de

sufrimiento mental: 20,60 (severo).

$5 \%$ varones.

cercanía equipos peligrosos,

\section{Intermediarios (6\%).}

$1 \%$ mujeres.

Edad promedio: 32,90 años.

Ingreso medio: 447 USD

\section{Media de exposición $(6,10)$. Procesos destructivos}

físicos, sedentarismo,

trabajo sin equipo de

protección.

Media de patologías

diagnosticadas $(2,5)$

Enfermedades crónicas:

diabetes, obesidad,

hipertensión y cáncer.

Media de estrés laboral:

6,40 (moderado). Media de

sufrimiento mental: 18,50

(severo).

Crianza de animales (2\%).

$1 \%$ mujeres.

$1 \%$ varones.

Edad promedio: 60 años.

Ingreso medio: 203 USD

Media de patologías

diagnosticadas $(3,00)$.

Infecciones respiratorias,

digestivas, dérmicas, $y$

oculares.

Media de estrés laboral: 27
Media de exposición

$(11,00)$.

Procesos destructivos

físicos, químicos,

biológicos, grandes

esfuerzos físicos, posturas

forzadas, cercanía equipos

peligrosos. Trabajo directo

sobre el vertedero sin

equipo de protección.
Media de IMC $(28,90)$.

$80 \%$ de los clasificadores

tienen sobrepeso.

Menor musculatura, en su mayoría mujeres, muchas presentan sobrepeso. Menor presencia de micosis e irritaciones.

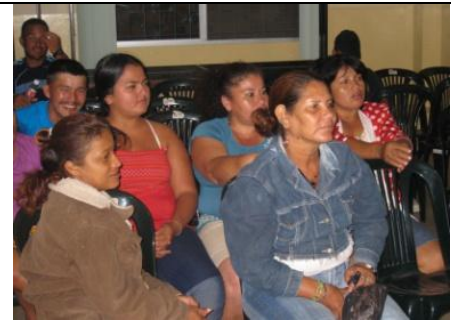

Media de IMC (34,52).

Sobrepeso u obesidad en todos los miembros de la familia. Piel menos

oscurecida por el sol, no presentan micosis.

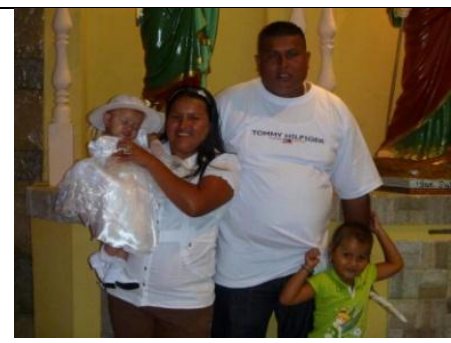

(severo). Media de

sufrimiento mental: 24,50

\section{Media de IMC (22,14).}

Similar al fenotipo de

clasificadores, excepto los

criadores de cerdos que son

delgados como los

recolectores.

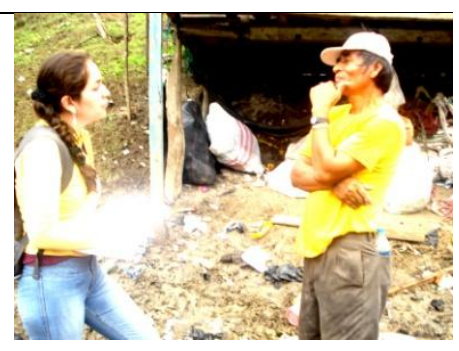


dermatológicos (Wilson y col., 2006; Ezeah y col., 2013). Los casos más severos reportados en una investigación realizada por Eerd (1996), fueron en comunidades que viven dentro o al lado de vertederos. Medina y Dows (2000) informó que recicladores de la ciudad de México tienen una esperanza de vida de 39 años, mientras que la población general tiene 67 años. Las principales patologías identificadas en nuestro estudio de caso (recolectores y sus familias) fueron: enfermedades infectocontagiosas, micosis, infecciones digestivas, infecciones urinarias (agentes biológicos), cefaleas y náuseas, intoxicación aguda y crónica por metano (agentes físicos y químicos), hipoacusia, tensión nerviosa, estrés e hipertensión arterial (ruido), pérdida momentánea de la visión, alergias, y problemas respiratorios y pulmonares (polvos irritantes), lumbalgia, dolores osteoarticulares (postura y esfuerzos), intoxicación por plomo (residuos eléctricos y electrónicos e industriales). La literatura revisada refiere el mismo perfil epidemiológico, y enfatiza especialmente en la presencia de gripes químicas, bronquitis, úlceras, hipertensión arterial, problemas musculares como dolor crónico de espalda (Gutberlet y Baeder, 2008; Matter y col., 2013).

Una investigación realizada por Eerd (1996), propone un estudio de casos comparativos entre recicladores y no recicladores, determinando que la población recicladora reportaba haber tenido un mayor número de problemas de salud, tenían peor estado nutricional, menor altura que la media (desnutrición crónica), dolores crónicos de espalda, debilidad general, tos crónica. Muchos habían sufrido cortes y lesiones con palos y agujas, la prevalencia de infecciones oculares y otros problemas oftalmológicos se veía incrementada (en nuestro estudio se reportan cerca de 30 casos de Pterigium), muchos habían sufrido mordeduras de ratas y perros, tenían problemas de piel, diarrea frecuente y referían uno o más episodios de ictericia en el último año.

Nuestra investigación, además de analizar la prevalencia de patologías, estudia los efectos de la exposición sistemática a biogás, compuesto esencialmente de metano. La literatura revisada concluye que la exposición a biogás es causante de los problemas respiratorios, dermatológicos, infecciones oculares y una baja esperanza de vida (Wilson y col., 2006; Ezeah y col., 2013). Eerd (1996) describe que trabajadores del turno de noche de un vertedero se quejaron de padecer alucinaciones severas.

Mediante la aplicación del reactivo Pentox, la investigación identificó la sintomatología derivada de exposición a metano reportada en recicladores/as: dificultad para respirar y ahogo, náuseas y vómitos, cefaleas, palpitaciones del corazón, mareos, visión borrosa, irritación ocular, síntomas gripales, falta de coordinación motora, malestar mental y letargo. Adicionalmente, problemas cognitivos, condiciones como pérdida de memoria y falta de juicio se reportaron en casos de personas con exposición prolongada (15 años o más).

El $45 \%$ de los actores de la economía informal del reciclaje puntuó en neurotoxicidad moderada y el $28 \%$ en neurotoxicidad severa. De éstos, el $93 \%$ de los casos de neurotoxicidad elevada corresponde a recolectores (quienes se encuentran directamente en contacto con los residuos) mientras que el $90 \%$ de los intermediarios presenta baja neurotoxicidad.

En adición a los aportes trabajados en relación a la determinación de la exposición, vulnerabilidad y perfil epidemiológico de recicladores informales, este trabajo da un salto importante en la investigación en tanto construye perfiles epidemiológicos o modos de vida diferenciales de acuerdo a la inserción que cada individuo tiene en la cadena laboral de la economía informal de la basura, cortando con la homogenización de grupos poblacionales marginales y demostrando que la salud (incluso el fenotipo) está determinada social y ambientalmente por las condiciones de explotación, opresión y desposesión propias del modelo de acumulación capitalista.

Además, las investigaciones citadas concuerdan con nuestra afirmación en relación a la segregación sociohistórica del territorio, en tanto concluyen que la proximidad a sitios de disposición final de residuos se encuentra asociada con ausencia de derechos sociales y económicos como saneamiento, agua potable, acceso a educación, salud y servicios de infraestructura (alumbrado, asfaltado de vías, etc.). 


\section{CONCLUSIONES Y RECOMENDACIONES}

Concluimos definiendo que existen cinco modos de vida derivados del tipo de actividad que se realice en la cadena del reciclaje y que éstos determinan los procesos de exposición, los procesos protectores, las condiciones de vulnerabilidad y las patologías presentes. Evidentemente en la cadena de explotación, son los recolectores (83\% del total) y criadores de cerdos quienes ocupan el primer peldaño, en tanto, además de percibir menor remuneración y trabajar durante más horas, son quienes tienen mayores niveles de exposición, vulnerabilidad, neurotoxicidad y enfermedades relacionadas al basural. En el segundo nivel de explotación estarían los chamberos, también con salarios mínimos que si bien no trabajan sobre el vertedero, tienen contacto directo con los residuos mezclados en las volquetas y carros recolectores. Los clasificadores seguirían en la escala, (promedio salarial mayor y espacios: doméstico y laboral alejados del basural). Finalmente, tendríamos a los intermediarios, quienes menos expuestos se encuentran y tienen mejores condiciones salariales y vitales (barrio en el que se ubican), los comercializadores cierran el circuito.

La eficiencia energética del reciclaje ha sido probada y promovida desde visiones de justicia social y ambiental (Gutberlet, 2008; Tangri, 2009; Solíz 2011), sin embargo, los obstáculos frecuentemente reportados por las municipalidades son la escasez y la debilidad de organizaciones autónomas de la sociedad civil, el dominio de tradicional verticalista y no participativa, el estilo de administración pública municipal, y el arraigo de una relación patrón-cliente entre los funcionarios del gobierno local y la gente de las comunidades con una falta de conciencia cívica asociada (Charuvichaipong y Sajor, 2006).

En muchos países, las políticas públicas en torno al sector informal del reciclaje son negativas, se caracterizan por la represión, la prohibición y la ausencia de apoyo (Wilson y col., 2006), esto además va de la mano de la venta, desde sectores privados nacionales y multinacionales, de tecnologías de eficiencia energética que pretenden mercantilizar la basura a costa de los recicladores informales (Tangri, 2009; Solíz, 2011).

Es en este sentido y en concordancia con otros muchos estudios, que enfatizamos en el fortalecimiento de las redes asociativas de recicladores, locales, nacionales y globales como base fundamental para la reivindicación de condiciones laborales dignas y derechos sociales, económicos y políticos (Gutberlet, 2008; Paul y col., 2012; Ezeah y col., 2013). A través de estos procesos de cooperativización o asociación, no solo que todos los actores de la economía informal del reciclaje tendrían mejores condiciones económicas de comercialización y venta (en tanto se corta con la cadena de intermediación) sino que sería más sencillo demandar su inclusión dentro de las políticas públicas de gestión integral de residuos. Frente a esta situación, existen múltiples retos que, partiendo de la implementación positiva de leyes, ordenanzas municipales y políticas públicas del modelo Basura $\mathrm{Cero}^{10}$, han incluido a los actores informales de la economía del reciclaje en modelos regidos por el enfoque de justicia social y ambiental.

Las iniciativas de Basura Cero agrupan múltiples experiencias en diversos países del mundo con distintos alcances y conquistas. Algunas ciudades han implementado desde 1995 políticas de Basura Cero con diversas variantes en tanto la continuidad de la política, la radicalidad de las definiciones, la escala de aplicación y el éxito de las iniciativas. Los objetivos de la Ley Basura Cero son: reducir progresivamente los materiales no retornables, rechazar y prohibir materiales no reciclables, reducir la cantidad de residuos, disminuir los riesgos para la salud pública y el ambiente, desarrollar

\footnotetext{
${ }^{10}$ A principios de los 80', un pequeño grupo de expertos en reciclaje comenzó a hablar acerca de la idea del "reciclaje total". De estas deliberaciones se llegó al concepto de "basura cero". En 1990, activistas de Filipinas ya utilizaban el término "Basura Cero". Una de las primeras políticas formales de "basura cero" fue creada en 1995, cuando Canberra, Australia, promovió el objetivo "Ningún desecho en el 2010”. Desde 1995, la propuesta "Basura Cero" ha sido promovida como objetivo por gobiernos en Nueva Zelanda; Dinamarca; Seattle y Washington, el condado Del Norte en California, San Francisco, California; el condado de Santa Cruz en California; Edmonton en Alberta; Ottawa, Ontario; y Nova Scotia. Asimismo, una serie de empresas nacionales e internacionales adoptaron algunos de los principios de "Basura Cero" como Greenpeace en Argentina (2013). Descargado de http://www.greenpeace.org/argentina/es/campanas/contaminacion/basuracero/ en octubre de 2013.
} 
instrumentos de planificación, inspección y control, desarrollar una progresiva toma de conciencia por parte de la población, desarrollar políticas de responsabilidad extendida al productor, promover el aprovechamiento de los residuos sólidos urbanos, fomentar la participación de asociaciones de recicladores/as y de empresas pequeñas.

Las soluciones no son sencillas y evidentemente no requieren aproximaciones tecnológicas, requieren decisión política soberana desde los tomadores de decisiones en los Estados nacionales, pero también y de manera especial, requieren una ciudadanía activa que rechace este perverso y aberrante modelo lineal y que sea parte de la construcción de otras formas de vivir saludables, soberanas, solidarias y reparadoras del metabolismo social.

\section{AGRADECIMIENTOS}

Esta investigación forma parte de la Tesis Doctoral: "Metabolismo del desecho en la determinación socioambiental de la salud", para la obtención del título de $\mathrm{PhD}$ en Salud Colectiva, Ambiente y Sociedad por la Universidad Andina Simón Bolívar. Mi agradecimiento y reconocimiento a todas las comunidades de afectados por sistemas de disposición final de residuos, a los recicladores y recicladoras informales; con ellos y ellas compartimos días y noches de trabajo en la búsqueda de justicia social y ambiental. Gracias también se deben a los colegas fraternos de GAIA, Greenpeace, Taller Ecologista, Movimiento por la Salud de los Pueblos, a la Universidad Andina Simón Bolívar, primordialmente al Doctorado en Salud Colectiva, Ambiente y Sociedad, al Dr. Jaime Breilh director del doctorado y de esta investigación. Por último, me gustaría expresar un sincero agradecimiento a los pares académicos que revisaron este artículo y al editor de la revista por sus valiosos aportes.

\section{BIBLIOGRAFÍA}

Ali, M., 1999. The informal sector: What is it worth? Waterlines, 17(3), 10-2.

Ander-Egg, E., 2003. Repensando la investigación-acción participativa. 2003 (4a ed.). Grupo Editorial Lumen Hvmanitas, Buenos Aires, Argentina, 151 pp.

Bauman, Z., 2005. Vidas desperdiciadas: la modernidad y sus parias. Editorial Paidós Iberica, Barcelona, España, 176 pp.

Berthier, H. C., 2003. Garbage, work and society. Resour. Conserv. Recy., 39(3), 193-210.

Bonfanti, F., 2004. Los residuos sólidos urbanos. Universidad Nacional del Nordeste, Facultad de Humanidades, Argentina, 10 pp. Descargado de http://www.ecoportal.net/Temas_Especiales/ Basura_Residuos/Los_Residuos_Solidos_Urbanos el 12 de agosto de 2013.

Breilh, J., 1993. Trabajo hospitalario, estrés y sufrimiento mental ( $1^{\mathrm{a}}$ ed.). Universidad Autónoma Metropolitana, México D.F., 23, 21-37.

Breilh, J., N. Pagliccia, A. Yassi, 2012. Chronic pesticide poisoning from persistent low-dose exposures in Ecuadorean floriculture workers: toward validating a low-cost test battery. Int. J. Occup. Environ. Health, 18(2), 7-21.

Breilh, J., 2003. Epidemiología crítica: Ciencia emancipadora e interculturalidad (2a ed.). Editorial Lugar, Buenos Aires, Argentina, 320 pp.

Charuvichaipong, C., E. Sajor, 2006. Promoting waste separation for recycling and local governance in Thailand. Habitat Int., 30, 579-594.

Chávez G., J. Daza, 2003. Reflexión metodológica sobre la aplicación concreta de la investigación acción participativa (IAP) en contextos rurales del Estado de Colima. Estudios sobre las culturas contemporáneas, 9(17), 115-146.

Damghani, A., G. Savarypour, E. Zand, R. Deihimfard, 2008. Municipal solid waste management in Tehran: Current practises, opportunities and challenges. Waste Manage., 28, 929-934. 
Eerd, V., 1996. The occupational health aspects of waste collection and recycling. A survey of the literature. WASTE Working Document 4, Part 1, Urban Waste Expertise Program (UWEP), 74 pp. Descargado de http://docs.watsan.net/Downloaded_Files/PDF/Eerd-1996-Occupational. pdf en marzo de 2013.

Ezeah, C., J.A. Fazakerley, C.L. Roberts, 2013. Emerging trends in informal sector recycling in developing and transition countries. Waste Manage., 33, 2509-2519.

Fals Borda, O., 2008. Orígenes universales y retos actuales de la IAP (investigación acción participativa). Peripecias $\mathrm{N}^{\circ} 110$. Disponible de $h t t p: / / w w w . p e r i p e c i a s . c o m / m u n d o /$ 598FalsBordaOrigenesRetosIAP.html.

Ferreira, J., L. Anjos, 2001. Aspectos de saúde coletiva e ocupacional associados à gestão dos resíduos sólidos municipais. Cad. Saúde Pública, 17(3), 689-696.

Freire, P., 1973. Pedagogía del oprimido. Tesis de doctorado. Editores Tierra Nueva y Siglo XXI, Buenos Aires, Argentina, 175 pp.

Goldberg, D., 1978. Manual for the general health questionnaire. National Foundation for Educational Research, Windsor, UK.

Greenpeace Argentina, 2013. Basura cero. Qué es basura cero. Argentina. Descargado de http://www.greenpeace.org/argentina/es/campanas/contaminacion/basura-cero/ en octubre de 2013.

Gutberlet, J., 2008. Empowering collective recycling initiatives: Video documentation and action research with a recycling co-op in Brazil. Resour. Conserv. Recy., 52, 659-670.

Gutberlet, J., A. Baeder, 2008. Informal recycling and occupational health in Santo Andre, Brazil. Int. J. Environ. Heal. R., 18, 1-15.

Matter, A., M. Dietschi, C. Zurbrügg, 2013. Improving the informal recycling sector through segregation of waste in the household - The case of Dhaka Bangladesh. Habitat Int., 38, 150-156.

Medina, M., 2003. Serving the unserved: informal refuse collection in Mexican cities. In: Solid waste collection that benefits the urban poor. CWG Workshop, Dar es Salaam, Tanzania, Paper No. 17, 88 pp. Descargado de http://www.skat.ch/publications/ prarticle.2005-09-

29.7288084326/prarticle.2005-11-25.5820482302/skatpublication.2005-12-02.0331566765/file en junio 2013.

Medina, M., M. Dows, 2000. A short history of scavenging. Comparative Civilizations Review, 42, 717.

Monirozzaman, S., Q. Bari, T. Fukuhara, 2011. Recycling practises of solid waste in Khulna City, Bangladesh. J. Solid Waste Technol. Manage., 37, 1-15.

Paul, J.G., J. Arce-Jaque, N. Ravena, S.P. Villamor, 2012. Integration of the informal sector into municipal solid waste management in the Philippines - What does it need? Waste Manage., 32, 2018-2028.

Rego, R. M. Barreto, C. Killinger, 2002. O que é lixo afinal? Como pensam mulheres residentes na periferia de um grande centro urbano. Cad. Saúde Pública, 18(6),1583-1592.

Rojas, J., 2002. Investigación Acción-Participativa (IAP), 5 pp. Universidad de los Andes, Venezuela. Descargado de http://www.comminit.com/la/lapm/sld-1947.html en marzo de 2013.

Samaja, J., 1994. Epistemología y metodología: elementos para una teoría de la investigación científica (Edición ampliada). Editorial Eudeba, Buenos Aires, Argentina, 382 pp.

Scheinberg, A., S. Spies, M.H. Simpson, A.P.J. Mol, 2011. Assessing urban recycling in low- and middle-income countries: Building on modernised mixtures. Habitat Int., 35, 188-198.

Schmelkes S., 1986. Fundamentos teóricos de la investigación acción participativa. En Picón, C. (Coord.). Investigación participativa: Algunos aspectos críticos y problemáticos. Biblioteca Digital CREFAL, pp.74-86. Disponible de http://www.crefal.edu.mx/biblioteca_digital/ coleccion_crefal/cuadernos/cual8/cap3.pdf.

Sembiring, E., V. Nitivattananon, 2010. Sustainable solid waste management toward an inclusive society: Integration of the informal sector. Resour. Conserv. Recy., 54, 802-809. 
Silva, A., R. Silveira Bernardes, L.R. Santos Moraes, J. D’Arc Parente dos Reis, 2002. Critérios adotados para seleção de indicadores de contaminação ambiental relacionados aos resíduos sólidos de serviços de saúde: uma proposta de avaliação, Cad. Saúde Pública; 18(5), 1401-1409.

Solíz, F., 2011. La cartografía de la basura en el Ecuador. Fundación Acción Ecológica, Quito, Ecuador, 12 pp. Descargado de http://www.accionecologica.org/images/2005/desechos/ alertas/alerta_6.pdf en agosto de 2013.

Solíz, F., 2013. Metabolismo del desecho en la determinación socioambiental de la salud. Tesis doctoral (no publicada), Universidad Andina Simón Bolívar, Quito, Ecuador, 457 pp.

Tangri, N., 2010. Respeto a los recicladores: Protegiendo el clima a través de basura cero. Alianza Global para Alternativas a la Incineración (www.no-burn.org), Buenos Aires, Argentina, 8 pp. Descargado de http://noalaincineracion.org/wp-content/uploads/Respeto-a-los-Recicladores.pdf en octubre 2013.

Toledo, V., M. Gonzáles de Molina, 2007. El metabolismo social: las relaciones entre la sociedad y la naturaleza. En: Garrido, F., M. González de Molina, J.L. Serrano, J.L. Solana (Eds.). El paradigma ecológico en las Ciencias Sociales. Editorial Icaria, Barcelona, España, 304 pp.

Veraza, J., 2008. Subsunción real del consumo al capital. Editorial Itaca, México, 333 pp. Descargado de http://jorgeveraza.com/sites/default/files/Subsunci\%C3\%B3n\%20 real\%20del\%20consumo_0.pdf en octubre de 2013.

Wilson, D.C., A.O. Araba, K. Chinwah, C.R. Cheeseman, 2009. Building recycling rates through the informal sector. Waste Manage., 29, 629-635.

Wilson, D.C., C. Velis, C. Cheeseman, 2006. Role of informal sector recycling in waste management in developing countries. Habitat Int., 30, 797-808.

Zen, I.S., Z.Z. Noor, R.O. Yusuf, 2014. The profiles of household solid waste recyclers and nonrecyclers in Kuala Lumpur, Malaysia. Habitat Int., 42, 83-89. 